\title{
Model Pertumbuhan Sapi Perah Friesian Holstein (FH) dari Lahir sampai Beranak Pertama di BBPTU-HPT Sapi Perah Baturraden Menggunakan Model Matematik Logistic
}

\author{
The Growth Model of Cows Friesian Holstein (FH) from Birth to the Frist Calf at BBPTU-HPT Baturraden \\ Using Logistic Mathematical Model
}

\author{
D. Ratnasari ${ }^{1}$, A. Atabany ${ }^{2}$, B. P. Purwanto ${ }^{3}$, \& L. B. Salma ${ }^{4}$ \\ ${ }^{1}$ Mahasiswa Pascasarjana Program Studi Ilmu Produksi dan Teknologi Peternakan. \\ ${ }^{2}$ Departemen Ilmu Produksi dan Teknologi Peternakan, Fakultas Peternakan, Institut Pertanian Bogor. \\ ${ }^{3}$ Program Studi Teknologi dan Manajemen Ternak Sekolah Vokasi, Institut Pertanian Bogor. \\ ${ }^{4}$ Departemen Ilmu Produksi dan Teknologi Peternakan, Fakultas Peternakan, Universitas Padjajaran. \\ Jln. Agatis, Kampus IPB Dramaga, Bogor, 16680, Indonesia \\ Jln. Lodaya II, Cilibende, Bogor Tengah, 16151, Indonesia \\ Jln. Raya Bandung Sumedang KM. 21, Hegarmanah, Jatinangor, Jawa Barat, 45363, Indonesia \\ No.Telp $=+6285375638493$ \\ Email koresponden author: ratnasaridesi2627@gmail.com
}

\begin{abstract}
This aims of this study is to first child by knowing growth model and creating a standard curve for dairy cattle growth at BBPTU-HPT Baturraden dairy cow in Baturraden district, Banyumas Regency, Purwokerto, Central Java. The data obtained form the primary data, were 353 tails and secondary data of births in 2005-2016 were 1437 tails and. Data were analyzed using SAS 9.4 program with NLIN procedures (Non Linear) using Logistic models. The results show that the Logistic model had a high degree of accuracy with the coefficient of determination $\left(R^{2}\right) 99.80 \%$.
\end{abstract}

Keywords: Friesian Holstein (FH), Logistic Model, growth model

\section{PENDAHULUAN}

Perkembangan peternakan sapi perah di suatu daerah dapat dilihat dari peningkatan populasi ternak, peningkatan produksi susu dan kualitas susu yang dihasilkan di daerah tersebut. Peningkatan jumlah populasi sapi perah dengan produksi susu yang terjadi sekarang ini belum sebanding dengan kebutuhan susu dalam negeri, sehingga jumlah impor susu masih tinggi. Konsumsi susu per kapita yang dipenuhi dari produksi dalam negeri (8708 $\mathrm{kg} /$ tahun) dengan total populasi sapi perah di Indonesia 544.791 ekor (Statistik Peternakan dan Kesehatan Hewan 2017).

Sapi Friesian Holstein (FH) berasal dari Provinsi Friesland Barat dan Holland Utara yang beriklim sedang (temperate) dengan empat musim yaitu musim semi, musim panas, musim gugur dan musim dingin (Blakely dan Bade 1991; Pane 1986). Sapi FH memiliki kemampuan memproduksi susu tinggi dengan kadar lemak lebih rendah dibandingkan bangsa sapi perah lainnya. Produksi susu sapi perah FH di negara asalnya mencapai 6000-8000 kg/ekor/laktasi, sedangkan di Inggris sekitar $35 \%$ dari total populasi sapi perah dapat memproduksi hingga 8069 kg/ekor/laktasi (Arbel et al. 2001). Sifat sapi perah umumnya tenang, jinak dan mudah beradaptasi (Pane 1986). Oleh karena itu, di Indonesia banyak dipelihara sapi FH baik skala perusahaan maupun peternakan kecil.

Pertumbuhan seekor ternak merupakan kumpulan dari pertumbuhan bagian-bagian setiap komponennya yang dapat dilihat dari penampilan fisik dan bobot hidupnya. Pertumbuhan memiliki dua aspek, yaitu: peningkatan massa per satuan waktu dan perubahan bentuk serta komposisi sebagai akibat dari pertumbuhan diferensial komponen-komponen tubuh (Berg dan Butterfield 1976; Tulloh 1978; Edey 1983; Lawrie 2003). Pertumbuhan menurut Williams (1982) adalah perubahan bentuk atau ukuran seekor ternak yang dapat dinyatakan dengan panjang, volume ataupun massa. Lawrence dan Fowler (2002) menjelaskan bahwa pertumbuhan adalah salah satu sifat utama dari setiap makhluk hidup. Pertumbuhan ternak merupakan kenaikan bobot skor ternak sampai mencapai ukuran dewasa tubuh (Montiel dan Ahuja 2005). Pertumbuhan yang rendah mengakibatkan sapi FH dara bertubuh kecil, terhambatnya dewasa kelamin, terlambatnya beranak pertama dan produksi susu menjadi rendah (Toharmat dan Suryahadi 1997).

Kurva pertumbuhan merupakan cerminan kemampuan suatu individu atau populasi untuk mengaktualisasikan diri sebagai ukuran berkembangnya 
bagian-bagian tubuh sampai ukuran maksimal (dewasa) pada kondisi lingkungan yang ada Lawrence dan Fowler (2002). Secara umum pertumbuhan berbentuk sigmoid atau "S". Kurva "S" menggambarkan suatu bentuk percepatan dan perlambatan yang dibatasi oleh titik belok atau titik infleksi. Penentuan titik infleksi secara biologi sulit untuk ditentukan, namun dengan bantuan kurva pertumbuhan non linier masalah tersebut dapat dipecahkan. Nilai parameter $\mathrm{M}$ dalam kurva pertumbuhan sangat berperan dalam penentuan terjadinya titik infleksi. Titik infleksi adalah titik maksimum pertumbuhan bobot badan (Brody 1974).

Model Logistic pada dasarnya mengacu pada bentuk persamaan regresi logistik (Myers, 1990). Model ini menggunakan tiga parameter, yaitu $\mathrm{A}, \mathrm{b}$ dan $\mathrm{k}$ sebagai fungsi untuk menentukan titik infleksi. Parameter A adalah pertumbuhan yang terbatas atau bobot dewasa (asimtot), b adalah konstanta integral sedangkan $\mathrm{k}$ adalah laju pertumbuhan menuju dewasa. Ketiga parameter inilah dapat membentuk fungsi logistic baru sehingga dapat diinterpretasikan, yaitu ploting data antara Y (bobot badan) dan $\mathrm{X}$ (umur) akan membentuk kurva sigmoid. Hassen et al. (2004) melakukan penelitian membandingkan antara kurva non linear model Broody, Von Bertalanffy, Logistic dan Gompertz untuk membandingkan hubungan bobot badan dan waktu pada jantan muda dan sapi Angus dara. Hasilnya untuk perbandingan antar kurva pertumbuhan dalam individu ternak hanya model Logistic yang merupakan satu-satunya model yang mencapai konvergen pada 98\% dari individu yang diteliti. Penelitian ini bertujuan untuk mengetahui pola pertumbuhan sapi perah FH dan menduga bobot badan dari lahir sampai beranak pertama.

\section{MATERI DAN METODE}

Penelitian ini bertempat di Balai Besar Pembibitan Ternak Unggul dan Hijauan Pakan Ternak (BBPTUHPT) sapi perah Baturraden, Kemutug Lor Kecamatan Baturraden Kabupaten Banyumas, Purwokerto Jawa Tengah. Baturraden memiliki ketinggian tempat \pm 675 $\mathrm{m}$ diatas permukaan laut ( $\mathrm{dpl}$ ) yang tergolong kedalam dataran sedang (Soribasya 1980). Temperature rata-rata berkisar $18-28^{\circ} \mathrm{C}$, kelembaban $70-80 \%$ dengan curah hujan 6000-9000mm/tahun. Menggunakan 353 ekor sapi FH betina berumur baru lahir sampai 25 bulan. Alat yang digunakan berupa tongkat ukur dan pita ukur meteran Rondo.

Pengukuran parameter berupa:

1. Bobot badan, yaitu diperoleh dari hasil penimbangan atau dari hasil pengukuran lingkar dada menggunakan pita ukur kemudian dikonversi, dalam satuan $\mathrm{kg}$ (Santoso 2005).

2. Lingkar dada (b), yaitu melingkarkan sekeliling rongga dada dibelakang sendi bahu (os scapula), dalam satuan cm (Kujoro et al. 2009) (Gambar 1).

3. Panjang badan (a), yaitu mulai dari tepi tulang humerus sampai tulang duduk (tuber ischii), dalam satuan cm (Kujoro et al. 2009) (Gambar 1).

4. Tinggi pundak (c), yaitu mulai dari titik tertinggi pundak (os vertebra thoracalis) secara tegak hingga permukaan tanah, dalam satuan $\mathrm{cm}$ (Kujoro et al. 2009) (Gambar 1).
Data dianalisis menggunakan program SAS 9.4 untuk mendapatkan model kurva pertumbuhan menggunakan model Logistic (Brown et al. 1976), dengan bentuk matematis sebagai berikut.

$$
Y=A\left(1+e^{-k t}\right)^{-M}
$$

Keterangan:

A : Bobot tubuh dewasa (asimtot);

M : Nilai yang berfungsi dalam pencarian titik infleksi (bentuk kurva);

e : Logaritma dasar (2.718282);

$\mathrm{k}$ : Rataan laju pertumbuhan hingga ternak mencapai beranak pertama;

t : Waktu dengan satuan bulan

Untuk estimasi bobot badan dan umur pada saat infleksi menggunakan model Logistic dapat dihitung dengan rumus:

$$
\begin{gathered}
\text { Bobot infleksi }=\mathrm{A}(\mathrm{M} / \mathrm{M}+1)^{\mathrm{M}} \\
\text { Umur infleksi }=(\ln \mathrm{M}) / \mathrm{k}
\end{gathered}
$$

Keterangan:

A : Bobot tubuh dewasa (asimtot);

M : Nilai yang berfungsi dalam pencarian titik infleksi (bentuk kurva);

$\mathrm{k} \quad$ : Rataan laju pertumbuhan

\section{HASIL DAN PEMBAHASAN}

Hasil analisis kurva pertumbuhan dari lahir sampai beranak pertama, umur dan bobot titik infleksi pada sapi perah FH dengan menggunakan model kurva pertumbuhan Logistic (Tabel 1). Hasil penelitian menunjukkan bahwa nilai parameter A (bobot dewasa) model Logistic (497,2 $\mathrm{kg}$ ) lebih berat dibandingkan penelitian Anggraeni et al. (2008) di KPSBU Lembang dengan rata-rata bobot sapi saat beranak pertama 416,20 kg. Perbedaan ini dikarenakan waktu pengukuran yang berbeda. Model Gompertz dalam menduga bobot dewasa mempunyai bias yang rendah (Arango dan Van Vleck 2002). Nilai k merupakan laju pertumbuhan menuju bobot beranak pertama yang berhubungan dengan kecepatan pertumbuhan sapi perah

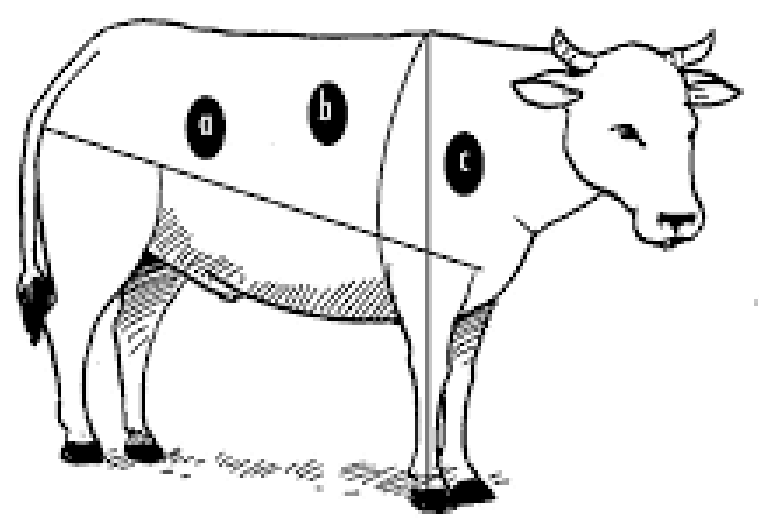

Gambar 1. Bagian-bagian tubuh yang diukur pada sapi 


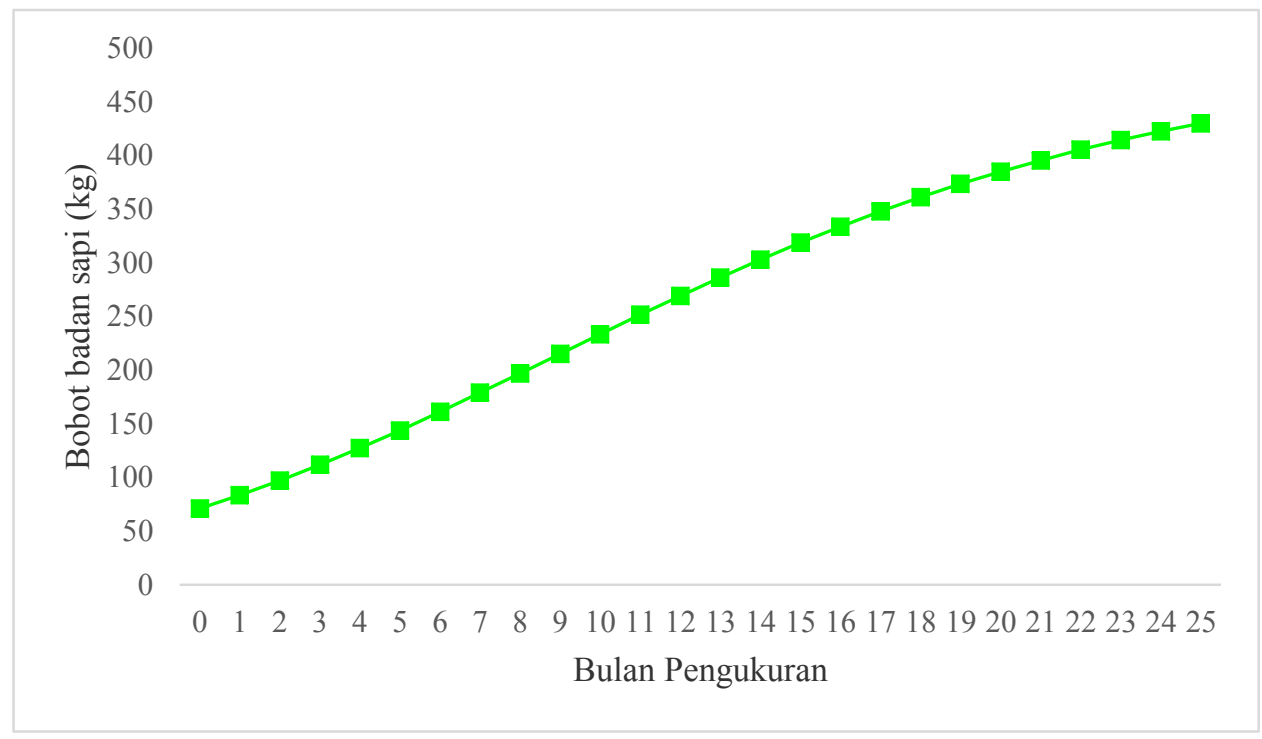

Gambar 2 .Kurva pertumbuhan sapi perah FH dari lahir sampai beranak pertama dengan model Logistic

Tabel 1. Persamaan model pertumbuhan sapi perah FH dari lahir sampai beranak pertama

\begin{tabular}{lccc}
\hline Model & Persamaan & t(i) (bulan) & $\mathrm{Y}(\mathrm{i})(\mathrm{kg})$ \\
\hline Logistic & $\mathrm{Y}=\mathrm{A}(1+\mathrm{e}-\mathrm{kt})-\mathrm{M}$ & & \\
& $\mathrm{Y}=497.2(1+\mathrm{e}-0.1174 \mathrm{t})-2.8066$ & 8,790 & 211,378 \\
\hline
\end{tabular}

Keterangan : $\mathrm{ti}=$ waktu infleksi (bulan); $\mathrm{Yi}=$ bobot saat titik infleksi $(\mathrm{kg}) ; \mathrm{e}=$ bilangan natural $(\mathrm{e}=2,718282) ; \mathrm{t}=$ waktu pencatatan (bulan)

FH pada model Logistic (0.1174). Grafik model Logistic tertera pada Gambar 2 .

Kurva pertumbuhan merupakan cerminan kemampuan suatu individu atau populasi untuk mengaktualisasikan diri sebagai ukuran berkembangnya bagian-bagian tubuh sampai ukuran maksimal (dewasa) pada kondisi lingkungan yang ada (Lawrence dan Fowler 2002). Secara umum pertumbuhan berbentuk sigmoid atau "S". Kurva "S" menggambarkan suatu bentuk percepatan dan perlambatan yang dibatasi oleh titik belok atau titik infleksi. Titik infleksi adalah titik maksimum pertumbuhan bobot badan (Brody 1974). Pada kurva pertumbuhan terjadi titik penting, yaitu titik infleksi pada saat mencapai pubertas. Hasil penelitian ini menunjukkan bahwa titik infleksi dicapai pada umur 8.8 bulan dengan bobot badan 211,4 kg. Lawrence dan Fowler (2002) menyatakan bahwa pubertas pada sapi perah terjadi pada umur 8-9 bulan. Folley et al. (1973) menyatakan bahwa sapi FH mengalami pubertas pada umur 8-12 bulan. Salisbury dan VanDemark (1985) menyatakan bahwa dengan pemberian pakan normal pada sapi FH di New York tercatat pubertas sapi dara pada umur 9 bulan dengan kisaran umur 5-15 bulan.

Perbandingan tingkat keakuratan model Logistic dalam menjelaskan data lapang dapat dilakukan dengan mengevaluasi perbedaan secara keseluruhan antara data lapang dengan data yang dihasilkan oleh parameter model kurva pertumbuhan. Perbandingan tersebut dapat dilakukan dengan menggunakan parameter simpangan data berupa koefisien deerminasi $\left(\mathrm{R}^{2}\right)$. Hasil koefisien determinasi $\left(\mathrm{R}^{2}\right)$ dengan menggunakan model pertumbuhan logistic mencapai 0.9980 lebih tinggi dibandingkan hasil penelitian Hossein-Zadeh (2017) di Iran dengan nilai koefisien determinasi model Logistic 0,95. Sama halnya dengan penelitian Nasri et al. (2008) terhadap sapi perah laktasi di Kanada dengan nilai koefisien determinasi model Logistic 0,82 dan penelitian Lopes et al. (2015) terhadap sapi perah laktasi dengan model Logistic 0,45 . koefisien determinasi sangat dipengaruhi oleh data terakhir penimbangan ternak. Perbandingan keakuratan data juga bisa dilihat dari jumlah iterasi pada model. Pada penelitian ini jumlah iterasi sedikit yaitu 8. Semakin banyak iterasi yang dilakukan berarti model tersebut semakin sulit mencapai konvergen. Hal ini sesuai dengan penelitian Budimulyati et al. (2012) dengan iterasi sebanyak 9 lebih sedikit dibanding model pertumbuhan lainnya. Perbedaan tersebut sangat dipengaruhi oleh perbedaan spesies yang menyebabkan perbedaan proses pertumbuhan, karena proses pertumbuhan berpengaruh terhadap perbedaan tingkat kemudahan estimasi parameter kurva pertumbuhan non linier (Budimulyati et al. 2015).

\section{KESIMPULAN}

Model matematik Logistic merupakan model yang mudah dalam perhitungan dengan jumlah iterasi yang sedikit dan mempunyai tingkat akurasi dengan nilai koefisien determinasi $\left(\mathrm{R}^{2}\right)$ 99.80\%. Pola pertumbuhan yang dihasilkan terlihat ideal membentuk huruf " $\mathrm{S}$ " dengan titik belok atau infleksi dicapai pada umur 8.8 bulan. Sehingga model ini mampu untuk menduga bobot badan sapi perah FH dari lahir sampai beranak pertama dengan melihat pola pertumbuhan yang terbentuk. 


\section{DAFTAR PUSTAKA}

Anggraeni, A., N. Kurniawan, \& C. Sumantri. 2008. Pertumbuhan pedet betina dan dara sapi friesianholstein di wilayah kerja bagian barat KPSBU Lembang. Seminar Nasional Teknologi Peternakan dan Veteriner 2008. 122-131.

Arango, J. A, \& L. D. Van Vleck. 2002. Size of beef cows: early ideas new development. Genet Mol Res. 1 (1): 51-63.

Arbel, G., D. Chalid, \& M. E. Ensminger. 2001. Karakteritik Sapi Perah Fries Holland. Institut Pertanian Bobor Press. Bogor.

Berg, R. T, \& R. M. Butterfield. 1976. New Concepts of Cattle Grownt. University Sydney Press, Sydney.

Blakely, J, \& D. H. Bade. 1991. Ilmu Peternakan. Edisi IV. Universitas Gajah Mada Press, Yogyakarta.

Brody, S. 1974. Bioenergetics and Growth : with special reference to the Efficiency Complex in Domestic Animals. New York. Hafner Press. A Division or Macmillan Publishing Co, Inc. Pp 489-493, 498, 502.

Brown, J. E., J. R. Fitzhugh, \& T. C. Cartwright. 1976. A comparison of nonlinear models for desecribing weight-age relationship in cattle. J Anim Sci. 42: 810-818.

Budimulyati, L. S., C. Sumantri., R. R. Noor., A. Saefuddin, \& C. Talib. 2012. Comparison on accuracy of logistic, gompertz and von bertalanffy models in predicting grownt of new born calf until first mating of holstein friesian heifers. JITAA. 37 (3): 151-160.

Budimulyati, L.S., C. Sumantri., R. R. Noor., A. Saefuddin, \& C. Talib. 2015. Kurva pertumbuhan sapi Friesian Holstein dari lahir sampai siap kawin berdasarkan tingkat kelahiran. J Veteriner. 16 (1): 96-106.

Edey, T. N. 1983. A Course manual in tropical sheep and goat production. Australia Universitas. International Development Program (AUIDP). Canberra.

Hassen, A., D. E. Wilson., G. H. Rouse, \& R. G. Tait. 2004. Use of linear and non linear growth curves to describe body weight changes of young angsung and heifers. Lowa State University Animal Industry Report.

Hossein-Zadeh, N. G. 2017. Application of growth models to describe the lactation curves for test-day milk production in Holstein cows. Journal of Applied Animal Research. 45(1):145-151.

Foley, R., D. L. Bath., F. N. Dickinson, \& H. A. Tucker. 1976. Dairy Cattle Principles Practices Problems Profits. Lea and Febriger. Philadelphia.

Kujoro, A., Sutarno, \& O. P. Astirin. 2009. Body weight and statistic vital of Texel sheep in Wonosobo District by giving the ramie hay as an additional woof. Nusantara Bioscience. 1(1):23-30.

Lawrence, T. L. J, \& V. R. Fowler. 2002. Growth of Farm Animals. $2^{\text {nd }}$ Edition., CABI Publishing, Oxon, UK., pp: 347.

Lawrie, R. A. 2003. Ilmu Daging. Edisi Kelima. Diterjemahkan oleh: A. Parakkasi. Universitas Indonesia Press, Jakarta.

Lopes, S., J. France., N. E. Odongo., R. A. McBride., E. Kebreab., O. Alzahal., B. W. McBride, \& Dijkstra.
2015. On the analysis of Canadian holstein dairy cow lactation curves using standard grownt functions. J Dairy Sci. 98: 2701-2712.

Montiel, F, \& C. Ahuja. 2005. Body condition score and sucking as factor influencing the duration of prostpartum anestrus in cattle a review. J Anim Rep Sci. 85: 1-26.

Myers, R. H. 1990. Classical and modern regresion with application. $2^{\text {nd }}$ Edition. Boston: PWS-KENT Publishing Company.

Nasri, M. H. F., J. France., N. E. Odongo., S. Lopez., A. Bannink, \& E. Kebreab. 2008. Modelling the lactation curve of dairy cows using the differentials of growth functions. J Agri Sci.146: 633-641.

Pane, I. 1986. Pemuliabiakan Ternak Sapi. PT. Gramedia, Jakarta.

Santoso, U. 2005. Tata Laksana Pemeliharaan Ternak Sapi. Penebar Swadaya, Jakarta.

Salisbury, G. W, \& N. L. VanDemark. 1985. Fisiologi reproduksi dan inseminasi buatan pada sapi. Diterjemahkan R. Djanuar. Universitas Gajah Mada, Yogyakarta.

Soribasya, S. 1980. Sapi perah. Jenis Teknik Pemeliharaan dan Analisa Usaha. Penebar Swadaya. Jakarta.

Statistik Peternakan \& Kesehatan Hewan. 2017. Direktorat Jenderal Peternakan Departemen Pertanian.

Toharmat, T, \& H. Suryahadi. 1997. Pemberian ransum anak sapi dan sapi dara. pelatihan manajemen pakan sapi perah untuk tenaga teknis koperasi/kud susu. Kerjasama Fakultas Peternakan IPB-GKSI-CCA. Bogor.

Tulloh, N. M. 1978. Growth, development, body composition, breeding and management. In: Tulloh NM (ed):A Course Manual in Beef Cattle.

Williams, I. H. 1982. A Course manual in nutrition and growth. Australian Vice-Choncellors-Committe, melbourne. 